\title{
Evaluation of Cardiovascular Activity of an Ayurvedic Product 'Mrityunjay' in Rat Model
}

\author{
Most. Shammi Rahman", Shahana Jahan ${ }^{1}$, Kamrun Nahar ${ }^{1}$, Nazia Islam ${ }^{1}$, Danis Rahman², \\ Ridwan Bin Rashid ${ }^{3}$, Abu Asad Chowdhury ${ }^{4}$, Rebecca Banoo ${ }^{1}$ and Mohammad Shah Amran ${ }^{4}$ \\ ${ }^{1}$ Department of Pharmacy, State University of Bangladesh, Dhanmondhi, Dhaka, Bangladesh \\ ${ }^{2}$ Department of Pharmacy, Jahangirnagar University, Savar, Dhaka, Bangladesh \\ ${ }^{3}$ Department of Microbiology, University of Dhaka, Dhaka-1000, Bangladesh \\ ${ }^{4}$ Department of Pharmaceutical Chemistry, Faculty of pharmacy, University of Dhaka, Dhaka, Bangladesh
}

\begin{abstract}
Ayurvedic system of medicine is a major component of indigenous systems of medicine in Bangladesh. We used an Ayurvedic drug 'Mrityunjay' which is traditionally used for high blood pressure, heart diseases and heartquake. We measured the electrocardiographical (ECG) parameters using an ECG machine (Vet 300, EDAN, China) in rat model before and after administration of the test drug. We observed that, Mrityunjay at high doses $(800 \mu \mathrm{g} / \mathrm{Kg}, 1600 \mu \mathrm{g} / \mathrm{kg}, 3200 \mu \mathrm{g} / \mathrm{kg}$ ) produced heart blocks and other arrhythmias, but in normal dose $(200 \mu \mathrm{g} / \mathrm{Kg})$ it has no serious untoward effects on cardiac muscle.
\end{abstract}

Key words: Ayurvedic, Mrityunjay, ECG, Cardiovascular disease, Ketamine.

\section{Introduction}

Ayurvedic system is one of the oldest systems of medicines, which has been practiced in this subcontinent for over 3000 years. Ayurveda meaning the science of life, is rooted in the social during the period $600 \mathrm{BC}$ to $700 \mathrm{AD}$ (Ghani, 2005). It is a medical system that deals not only with body but with the mind and spirit as well. According to Ayurveda, most diseases connected with the psychophysiologic and pathologic changes in the body are caused by imbalance in three different dosha (i.e. vata, pitta, and kapha). The fundamental aim of Ayurvedic therapy is to restore the balance between these three major body systems. Any imbalance can lead to inflammation (also called sopha) (Chopra and Doiphode, 2002; Garodia et al., 2007). This balance is necessary for contentment and good health. Ayurveda stresses the use of plant-based medicines. Hundreds of plant-based medicines are employed, some animal products may also be used. Ayurvedic formulations are consider to be safe and more effective in comparison to allopathic formulations which have more side effects (http://en.wikipedia.org/wiki/ Ayurveda). But there is not enough scientific evidence to support such claims.

Mrityunjay is a liquid Ayurvedic drug and it is used as an excellent tonic for high blood pressure, heart diseases and heart-quake. Its manufactured as a liquid preparation from arista process in which the main ingredients are khadira kashtho (Acacia catechu), arjun (Terminalia arjuna), nageshwar (Mesua ferre), brongo (Belleric myrobalan), amlaki (Emblica Officinalis), bohero (Terminalia belerica), shotomuli (Asparagus), jotamangshi (Spikenard), rasna (vanda roxburghii), jostimodhu (Glycyrrhiza glabra), alkushi, Indian long pepper, kakali (Roscoea Purpurea) etc., (Bangladesh National Formulary of Ayurvedic Medicine, 1992). The major active ingredients in Mrityunjay are epicatechin, atzelchin, gallonchin, kaempferol, triphala, phenolic acids, flavonoids and tannins. Arjun bark is rich in saponnins, natural anti-oxidants, gallic acid, ellagic acid, oligomeric proanthocyanidins, phytosterols, calcium, magnesium, zinc and copper (http://arjuna.co.in/aboutarjuna.html).

Among the novel instrumental techniques for diagnosis of cardiovascular diseases, ECG remains the most important and commonly used diagnostic procedure as it is noninvasive, easily available and easily repeatable (Erik and Bjarne, 1991). ECG tracings were analyzed following our previous paper (Amran et al., 2008)

The main objective of our study is to investigate the therapeutic efficacy of the Ayurvedic medicines available in Bangladesh using rat model. 


\section{Materials and Methods}

Drug: Mrityunjay was purchased from Sree Kundeswari Aushadhalaya Ltd., Chittagong, Bangladesh, It was presented as $500 \mathrm{~mL}$ in glass bottle.

Instrument: ECG machine (Edan Vet ECG 300, China) with six channels.

Animals: A total of 100 rats of either sex, weighing about 130-150g, aged about 2 month, were purchased from animal house of Department of Pharmacy, Jahangirnagar University. All the rats were acclimatized to new environment for a period of one week. During the experiment period the rats were kept in a well ventilated animal house at $25^{\circ} \mathrm{C}$. They were supplied with standard pellets and fresh drinking water. All the rats were kept in cage and maintained with natural $12 \mathrm{~h}$ light and dark cycle.

Anesthetic process: For anesthesia rats were given Ketamine at a dose of $50 \mathrm{mg} / \mathrm{kg}$ as intramuscular injection.

Machine setup: The electrode wires were connected to the left arm, right arm, left leg, right leg of rib joint. We selected auto option to get rhythm from standard limb lead I, II ,III, avR, avL, avF, V. Finally standard limb lead I and II were used for characterization of ECG.

Calculation of dose: The doses have been calculated from human dose of $10 \mathrm{~mL}$ once at a time. The dose calculation was given in the Table 1 .

Table 1. Calculation of dose (' $X$ ' is body weight).

\begin{tabular}{ccc}
\hline $\begin{array}{c}\text { Concentration } \\
\text { (as expressed by } \\
\text { "X”) }\end{array}$ & $\begin{array}{c}\text { Amount of drug } \\
\text { (as expressed by } \\
\mu \mathrm{g} / \mathrm{kg})\end{array}$ & Action sought \\
\hline $1 / 16 \mathrm{X}$ & 100 & Less action \\
$1 / 12 \mathrm{X}$ & 133 & Less action \\
$1 / 8 \mathrm{X}$ & 200 & Normal action \\
$1 / 4 \mathrm{X}$ & 400 & Slight toxic action \\
$1 / 2 \mathrm{X}$ & 800 & Toxic action \\
$\mathrm{X}$ & 1600 & Toxic action \\
$2 \mathrm{X}$ & 3200 & Lethal action \\
$4 \mathrm{X}$ & 6400 & Lethal action \\
$8 \mathrm{X}$ & 12800 & Lethal action \\
\hline
\end{tabular}

ECG parameters: Typical ECG tracings are consisted of series of waves that are known as $\mathrm{P}$ wave, QRS complex, $\mathrm{T}$ wave and $\mathrm{U}$ wave. Alongside these, PR interval, RR interval, ST segment, QT interval are also important parameters to identify the abnormalities in the electrical conduction system of the heart. Any disturbance in any of the waves, complexes or intervals indicate some type of arrhythmia or heart disease. These parameters are summarized in Table 2.

Table 2. ECG parameters are summarized in the table 2 (Braunwald 1997; Ganong 2005).

\begin{tabular}{lc}
\hline Parameters of ECG & Duration (ms) \\
\hline P wave & $\leq 100$ \\
QRS complex & $80-0.110$ \\
Q wave & 40 \\
R wave & 200 \\
S wave & $60-100$ \\
T wave & 160 \\
U wave & 80 \\
PR interval & $120-200$ \\
ST segment & $\leq 200$ \\
R-R interval & $600-1200$ \\
Q-T interval & $350-430$ \\
\hline
\end{tabular}

ECG paper speed: The paper moves at a rate of 25 $\mathrm{mm} / \mathrm{second}$. Time is measured horizontally. Each small block is $1 \mathrm{~mm}$ equal to 0.04 seconds and equal to $0.1 \mathrm{mV}$. Each bold block is equal to 0.2 seconds. Amplitude is measured vertically.

\section{Results and Discussion}

In control mode, the normal heart rate was 208-344 bpm, the range being 250-350 bpm (Figure 2). But when Mrityunjay was administered at a dose of $800 \mu \mathrm{g} / \mathrm{Kg}$, no change in the heart rate was observed (Figure 3) but at a dose of $1600 \mu \mathrm{g} / \mathrm{Kg}$, the heart rate decreased and several types of heart abnormalities were observed (figure 4 'a' and ' $\mathrm{b}$ ')

After administration of $3200 \mu \mathrm{g} / \mathrm{Kg}$ of the drug, the heart rate was decreased to about $75 \mathrm{bpm}$. It indicated that Mrityunjay produced a condition looking similar to fibrillation and ultimately leading to the death of the animals (Figure 5).

Data from Auto mode: The auto mode is that mode where heart rate, P wave, PR interval, QRS duration are shown. Using this auto mode we could know about increase or decrease of heart rate. The data obtained after administration of $800 \mu \mathrm{g} / \mathrm{Kg}$ were shown in table 3 . 


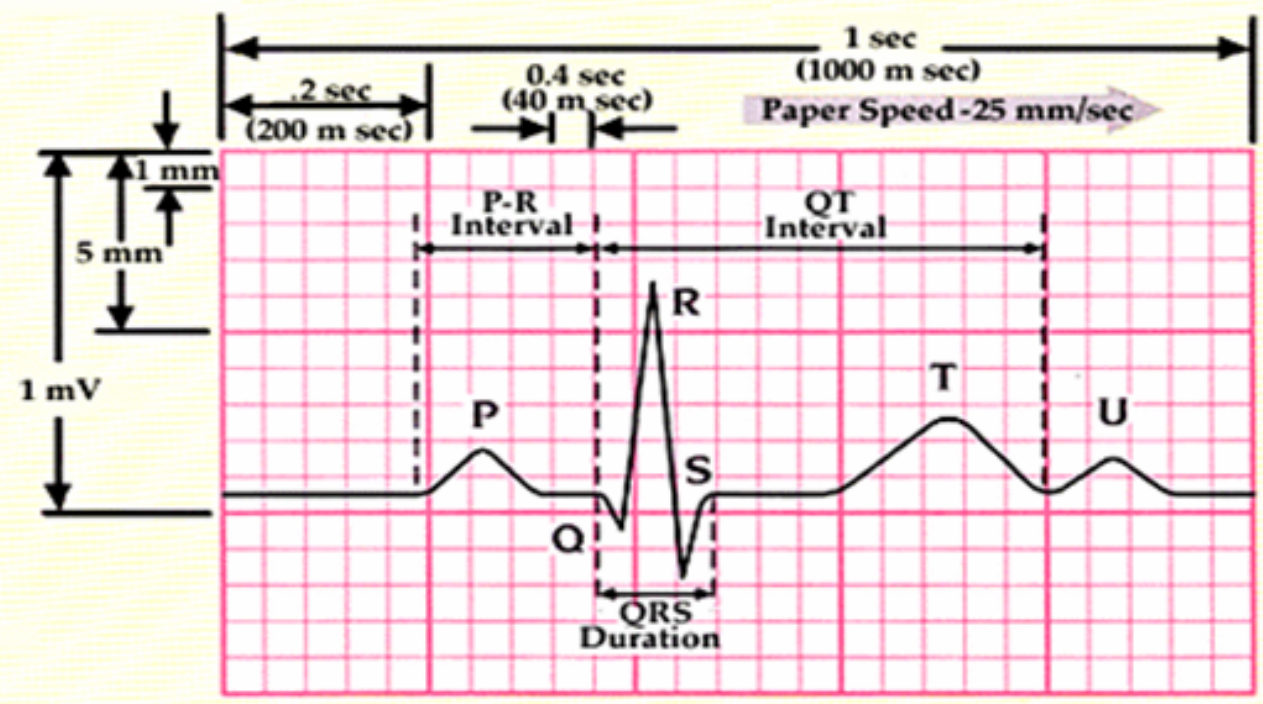

Vertical Axis

1 small square $=1 \mathrm{~mm}(0.1 \mathrm{mV})$

1 Large square $=5 \mathrm{~mm}(0.5 \mathrm{mV})$

2 Large square $=10 \mathrm{~mm}(1 \mathrm{mV})$

\section{Horizontal Axis}

1 small square $=0.04 \mathrm{~s}(40 \mathrm{~ms})$

1 Large square $=0.2 \mathrm{~s}(200 \mathrm{~ms})$

5 Large square $=1 \mathrm{~s}(1000 \mathrm{~ms})$

Figure 1. Schematic presentation of an ECG tracing (Erik and Sigurd, 1991)

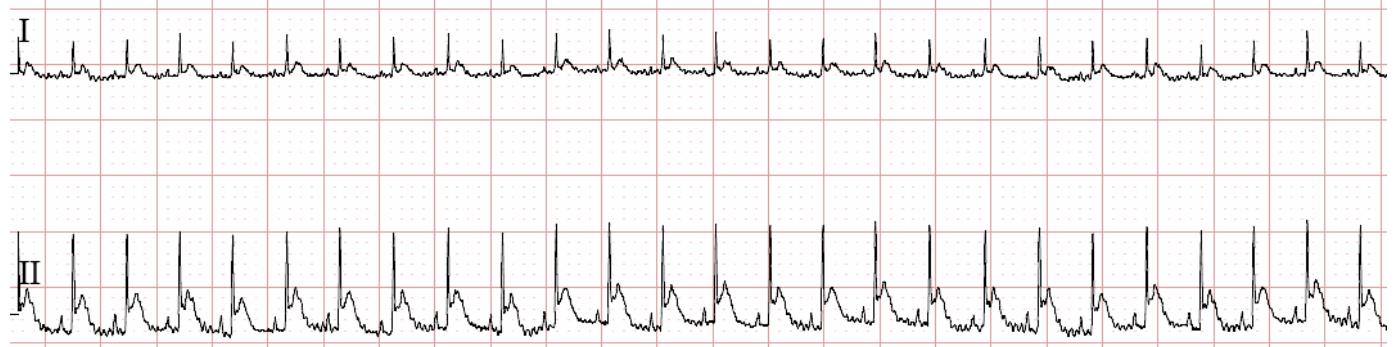

Figure 2. Normal sinus rhythm (NSR) of the rat heart. Only the tracings of the standard limb lead I and II shown. The vertical line indicates milivolt $(\mathrm{mV})$ and the horizontal line indicates time in second (s). The ECG tracings are chosen from one of the ten $(\mathrm{n}=10)$ similar and representative experiments.

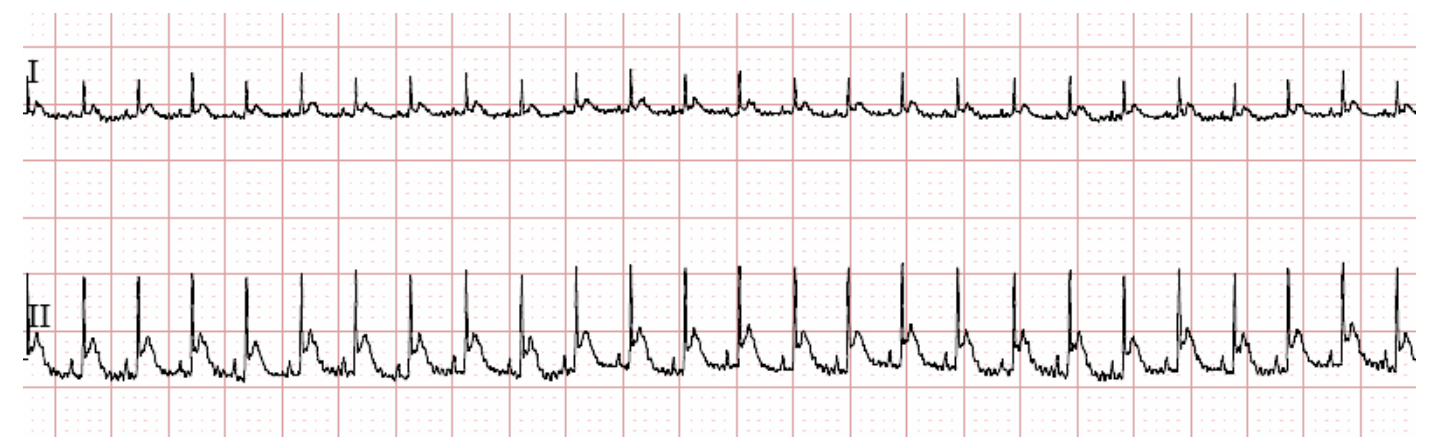

Figure 3. ECG tracing after administration of $800 \mu \mathrm{g} / \mathrm{Kg}$ of Mrityunjay. Tracings from limb lead I and II were shown. No abnormalities were found at this dose. 

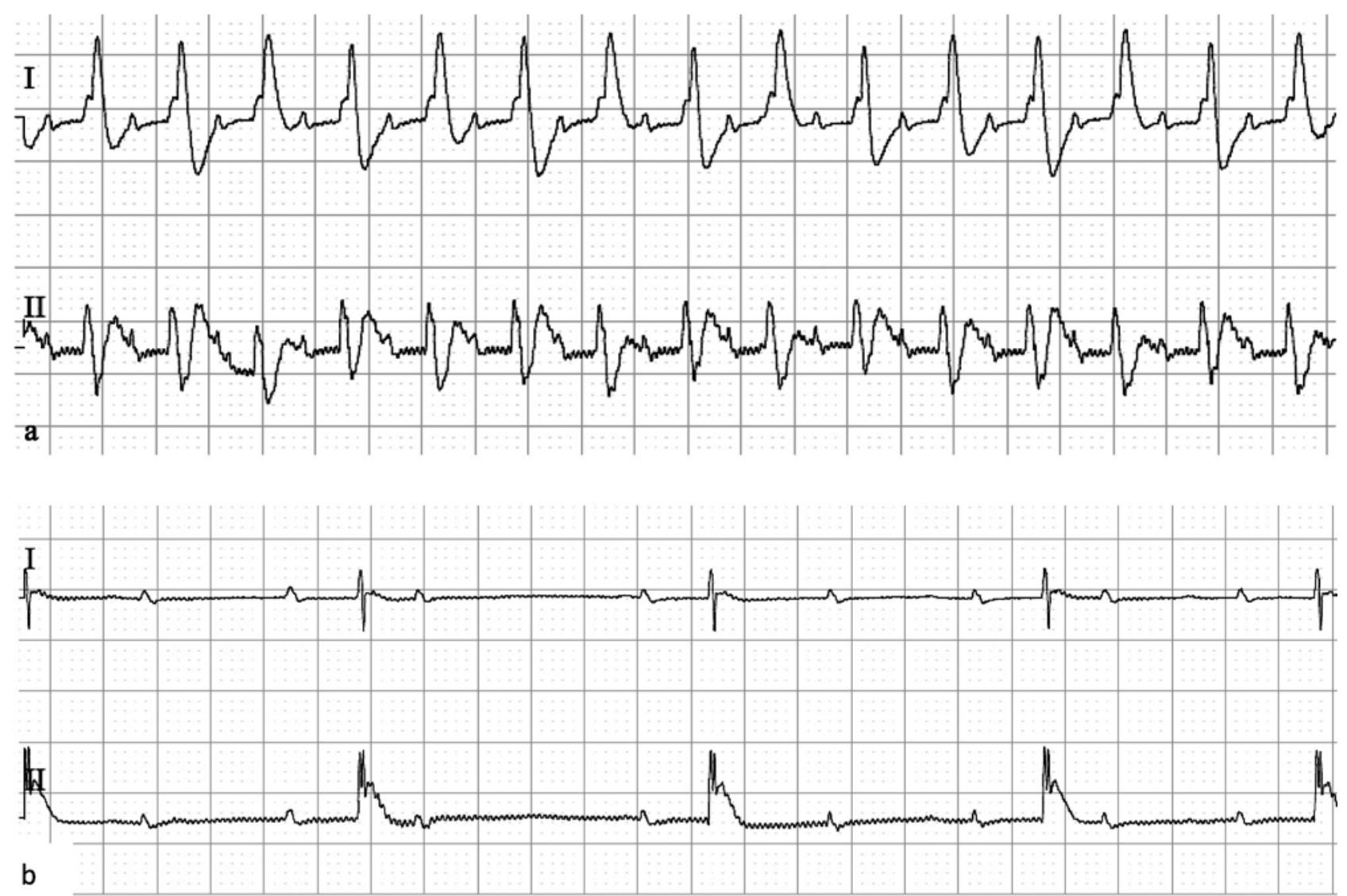

Figure 4. Typical ECG tracings of the standard limb lead I and II after intraperitoneal administration of $1600 \mu \mathrm{Kg} / \mathrm{Kg}$ of drug. Panel 'a' indicated wide QRS syndrome and panel 'b' indicates both SA nodal and AV nodal blocks. The vertical line indicates $\mathrm{mV}$ and the horizontal line indicates time in second (s). The ECG tracings are chosen from one of the $(\mathrm{n}=10)$ similar and representative experiments.

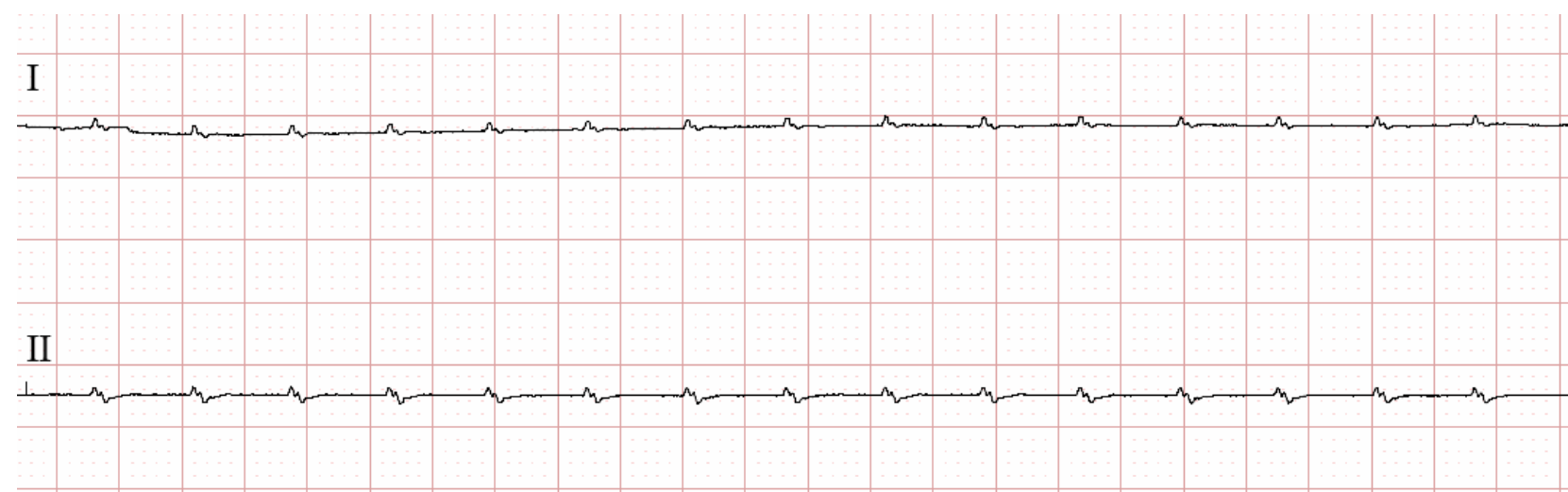

Figure 5. Typical ECG tracings of the standard limb lead I and II after intraperitoneal administration of $3200 \mu \mathrm{g} / \mathrm{Kg}$ of Mrityunjay. Only the tracings of the standard limb lead I and II are shown. Both lead I and II showed fibrillation and dying condition of the animal. The vertical line indicates $\mathrm{mV}$ and the horizontal line indicates time in second(s). The ECG tracings were chosen from one of the ten $(\mathrm{n}=10)$ similar and representative experiments. 
Table 3. Different ECG parameters after administration of Mrityunjay at a dose of $800 \mathrm{\mu g} / \mathrm{Kg}$. The data are shown as mean of 10 similar experiments $(n=10)$ in Auto mode.

\begin{tabular}{ccccc}
\hline Time $(\mathrm{min})$ & HR $(\mathrm{bpm})$ & P dur $(\mathrm{ms})$ & PR interval (ms) & QRS dur (ms) \\
\hline Pretreatment & 267.17 & 37.5 & 77.17 & 161.33 \\
10 & 251.5 & 44.83 & 89.83 & 172.5 \\
15 & $257 . .83$ & 44.5 & 89.83 & 166.16 \\
20 & 240.66 & 58.5 & 104 & 187 \\
25 & 270.17 & 53.67 & 94.5 & 168 \\
30 & 257.17 & 43.17 & 90.33 & 186 \\
35 & 256.33 & 37.6 & 91.2 & 143.17 \\
40 & 276 & 37 & 92.6 & 148.5 \\
45 & 273.33 & 39.6 & 72.4 & 148.5 \\
50 & 264 & 40 & 73.17 & 149.17 \\
\hline
\end{tabular}

The data obtained after administration of $1600 \mu \mathrm{g} / \mathrm{Kg}$ were shown in the table 4 .

Table 4. Different ECG parameters after administration of Mrityunjay at a dose of $1600 \mu \mathrm{g} / \mathrm{Kg}$. The data are shown as mean of 10 similar experiments $(n=10)$ in Auto mode.

\begin{tabular}{ccccc}
\hline Time $(\mathrm{min})$ & HR $(\mathrm{bpm})$ & P dur $(\mathrm{ms})$ & PR interval $(\mathrm{ms})$ & QRS dur $(\mathrm{ms})$ \\
\hline Pretreatment & 267.17 & 37.5 & 77.17 & 161.33 \\
10 & 250.17 & 37.5 & 85.17 & 180.67 \\
15 & 264 & 57.25 & 87.75 & 153.33 \\
20 & 254 & 38 & 66 & 125.5 \\
25 & 271 & 37.83 & 70.17 & 168.17 \\
30 & 259.33 & 41.2 & 102 & 128.67 \\
35 & 277.33 & 33.5 & 63.75 & 178.17 \\
40 & 269 & 39.5 & 90.50 & 135.75 \\
45 & 199 & 81.33 & 115.67 & 140.25 \\
50 & 195.5 & 46.33 & 101 & 166.25 \\
\hline
\end{tabular}

The data obtained after administration of $3200 \mu \mathrm{g} / \mathrm{Kg}$ were shown in the table 5 .

Table 5. Different ECG parameters after administration of Mrityunjay at a dose of $3200 \mu \mathrm{g} / \mathrm{Kg}$. The data are shown as mean of 10 similar experiments $(n=10)$ in Auto mode.

\begin{tabular}{ccccc}
\hline Time $(\mathrm{min})$ & HR $(\mathrm{bpm})$ & P dur $(\mathrm{ms})$ & PR interval $(\mathrm{ms})$ & QRS dur $(\mathrm{ms})$ \\
\hline Pretreatment & 267.17 & 37.5 & 77.17 & 161.33 \\
10 & 273.5 & 45 & 64 & 170 \\
15 & 302.5 & 37 & 58 & 184.5 \\
20 & 229.5 & 77 & 110 & 145 \\
25 & 106.5 & 98.5 & 154 & 171 \\
30 & 95.5 & 51 & 183 & 118.5 \\
35 & 106.5 & 37 & 156 & 118 \\
40 & 67 & 0 & 104 & 104 \\
45 & 75 & 0 & 0 & 89 \\
50 & 000 & 000 & 000 & 000 \\
\hline
\end{tabular}

Data from Rhythm mode: the rhythm mode is that mode where lead I, II, III, aVR, aVL, V is located. This mode showed RR avg interval, RR max interval, RR min interval. The data obtained after administration of $800 \mu \mathrm{g} / \mathrm{Kg}$ of drug were shown in the table 6 . 
Table 6. Different ECG parameters after administration of Mrityunjay at a dose of $800 \mathrm{\mu g} / \mathrm{Kg}$. The data are shown as mean of 10 similar experiments $(n=10)$ in Rhythm mode.

\begin{tabular}{cccccc}
\hline Time (min) & Total R number & HR (bpm) & RR avg interval & RR max interval & RR min interval \\
\hline Pretreatment & 192.4 & 241 & 257.8 & 540.4 & 186.25 \\
10 & 231.8 & 238.8 & 255.8 & 519.4 & 153.4 \\
15 & 247.2 & 249.2 & 257.8 & 467.6 & 192.75 \\
20 & 218.5 & 259.5 & 241.16 & 420.83 & 167.6 \\
25 & 266.2 & 268.4 & 235 & 367.4 & 160.25 \\
30 & 245.33 & 270 & 231.5 & 379 & 182 \\
35 & 282.2 & 282 & 213.4 & 405.2 & 195.5 \\
40 & 264.167 & 265.5 & 229.83 & 344.33 & 199.5 \\
45 & 249.83 & 251.5 & 242 & 391.16 & 188.83 \\
50 & 251.83 & 253.33 & 240.67 & 318.67 & 194.33 \\
\hline
\end{tabular}

The data obtained after administration of $1600 \mu \mathrm{g} / \mathrm{Kg}$ of drug were shown in the table 7.

Table 7. Different ECG parameters after administration of Mrityunjay at a dose of $1600 \mu \mathrm{g} / \mathrm{Kg}$. The data are shown as mean of 10 similar experiments $(n=10)$ in Rhythm mode

\begin{tabular}{cccccc}
\hline Time $(\mathrm{min})$ & Total R number & HR $(\mathrm{bpm})$ & RR avg interval & RR max interval & RR min interval \\
\hline Pretreatment & 192.4 & 241 & 257.8 & 540.4 & 186.25 \\
10 & 255 & 256.83 & 237.83 & 399.5 & 188.33 \\
15 & 224.83 & 256.67 & 237.167 & 290.67 & 222.33 \\
20 & 258.5 & 258.167 & 235.67 & 301.33 & 218.33 \\
25 & 287.33 & 289.83 & 210.167 & 250.67 & 200 \\
30 & 244 & 245.67 & 262.83 & 465.67 & 190.67 \\
35 & 284.75 & 286.75 & 213 & 343 & 177.75 \\
40 & 234 & 249.75 & 269.75 & 503.5 & 250 \\
45 & 114.25 & 168.5 & 698.75 & 1355.25 & 611.33 \\
50 & 190 & 214 & 588.75 & 1312.25 & 206 \\
\hline
\end{tabular}

The data obtained after administration of $3200 \mu \mathrm{g} / \mathrm{Kg}$ of drug were shown in the table 8.

Table 8. Different ECG parameters after administration of Mrityunjay at a dose of $3200 \mu \mathrm{g} / \mathrm{Kg}$. The data are shown as mean of 10 similar experiments $(n=10)$ in Rhythm mode.

\begin{tabular}{cccccc}
\hline Time (min) & Total R number & HR (bpm) & RR avg interval & RR max interval & RR min interval \\
\hline Pretreatment & 192.4 & 241 & 257.8 & 540.4 & 186.25 \\
10 & 287 & 289 & 213.5 & 1161 & 217 \\
15 & 221.5 & 223 & 294.5 & 1425 & 593.5 \\
20 & 161.5 & 163 & 378.5 & 1067 & 164.5 \\
25 & 92 & 92 & 649 & 1200 & 510 \\
30 & 54 & 54 & 1102 & 2614.5 & 682 \\
35 & 32 & 46 & 1316.5 & 1839 & 217 \\
40 & 48 & 47 & 1266 & 0 & 0 \\
45 & 0000 & 0 & 0 & 0 & 0 \\
\hline
\end{tabular}

\section{Conclusion}

From the above results and discussion, it can be inferred that Mrityunjay, in normal dose, is a safe drug but it should be used with caution and proper monitoring when higher doses are administered or taken chronically for long time. 


\section{References}

Amran, M. S., Keitaro, H. and Nobuo, H. 2008. Characterization of cardiac dysrhythmias induced by the modification of sodium channels and the inhibition of $\mathrm{Na}^{+}-\mathrm{K}^{+}$ATPase in guinea pigs; Saudi Pharm. J. 16, 50-57.

Bangladesh National Formulary of Ayurvedic Medicine. 1992. (Approved by the Government of Bangladesh vide Ministry of Health and Family Welfare Memo No. Health1/Unani-2/89/ (Part-1) 116, dated 3-6-1991, p. 121-123.

Braunwald, E. (Editor), 1997. Heart Disease: A Textbook of Cardiovascular Medicine; Fifth Edition; Philadelphia; W.B. Saunders Co., p. 108.

Chopra, A. and Doiphode, V.V. 2002. Ayurvedic medicine, core concept, therapeutic principles, and current relevance. Complemet Altern. Med. 86, 75-89.
Ganong, Review of Medical Physiology, $23^{\text {rd }}$ Edition, A LANGE medical book, pp. 490-503.

Ghani, A. 2005. Text Book of Pharmacognosy. 2nd Edition (part one), p. 240.

Garodia, P., Ichikawa, H., Malani. N,, Sethi, G. and Aggarwal, BB. 2007. From Ancient Medicine to Modern Medicine: Ayurvedic Concepts of Health and Their Role in Inflammation and Cancer. J. Soc. Integrative Oncology 5, 01-02.

Internet-1: http://en.wikipedia.org/wiki/Ayurveda.

Internet-2: http://arjuna.co.in/aboutarjuna.html.

Lindsay, A.E., ECG Learning Center, library.med.utah. edu/kw/ecg/mml/ ecg - 517.html, p.150.

Sandoe, E. and Signure, B. 1991. A Guide to Clinical Electrocardiology, pp. 1-34. 